\title{
The ontogeny of classical conditioning in the neonatal rat with varied CS-UCS intervals ${ }^{1}$
}

PHILIP H. GRAY, ALVIN E. YATES AND KAREN McNEAL MONTANA STATE UNIVERSITY

Leg flexion to shock after vibration was studied in neonatal rats during the first, third, sixth and twelfth days of age, using CS-UCS intervals of 300,600 and $1200 \mathrm{msec}$. Every tenth trial was a test trial (no UCS) for a block of 80 trials per $S$, and responses to CS that anticipated the UCS were measured during the other nine trials of a block. There was little hard evidence of learning during the early days of life, but conditionability steadily increased as a function of age. While on the first day of age the $1200 \mathrm{msec}$ interval produced more test trial CRs than the 600 msec interval, this phenomenon was reversed on the twelfth day of age.

Not until the experiment by Caldwell \& Werboff (1962) was the neonatal white rat subjected to classical conditioning of the type characterized by unavoidable reinforcement, molecular response, and nonoperant circumstances (Pavlovian procedure). The Caldwell-Werboff results are interesting in three respects. First, there was evidence of conditioning in day-old pups. Second, the more effective intervals were found to be 1200 and $2400 \mathrm{msec}$, longer than the optimum interval of $500 \mathrm{msec}$ cited by other investigators (cf., Kimble, 1961). Third, it was not possible to tell which response was used for the dependent variable: anticipatory movements occurring between the CS onset and the UCS onset, or responses that followed $\mathrm{CS}$ in test trials that had no UCS.

This experiment was designed to answer the following questions. (1) Granted that Caldwell and Werboff had demonstrated conditioning in day-old white rats, would learning increase with age? (2) Would there be other changes correlated with age? (3) Could we verify that longer intervals were more efficacious?

Method

Subjects. Experimental Ss were 48 albino rats randomly drawn from 12 litters. Control Ss were 12 rats similarly obtained.

Apparatus. Conditioning was carried out in a 12 x $8 \times 7$ in. compartment with a Plexiglas lid. The temperature was maintained at $90^{\circ} \mathrm{F}$ by a radiant heating element. The harness in which $\mathrm{S}$ was suspended was synthetic fabric mesh with holes provided for legs and the anterior surface of the abdomen, to which the vibrotactile CS was applied by a glass rod attached to a speaker cone for which the voice coil was driven by a $1 / 10$ V RMS $128 \mathrm{cps}$ signal from an audio generator. The UCS was a $50-\mathrm{msec}$ $1 \mathrm{~mA}$ dc pulse applied through S's foreleg via two felt-lined aluminum electrodes with flexible copper wire leads wetted with saline solution. A control system was built to monitor body resistance and to program intervals, duration of $\mathrm{CS}$, and intensity of UCS. The system also surveyed the possibility of breaks in the shocking circuit. A micro-displacement motion transducer was constructed by means of a $3 / 4 \times 1 / 16$ in. magnet taped to S's foreleg and suspended in a vertical plastic tube around which was wrapped a small coil of wire. Displacement of the magnet within the tube, which occurred whenever $S$ flexed its leg, generated a current in the coil, and this was fed into a polygraph amplifier with the output driving the pen of an oscillograph. Presentations of CS and UCS were recorded by event marker pens.

Experimental design. The experimental Ss were divided into four ages $(1,3,6$, and 12 days) by three CS-UCS delayed conditioning intervals $(300,600$, and 1200 msec from onset to onset) with 80 repeated measurements on each $S$ (elght blocks of 10 trials). The control Ss formed groups for the three intervals for the first day of age; they were treated like the other Ss except the shock circuit was disconnected.

Procedure. Ss were given eight blocks of conditioning trials at one setting. Each block consisted of nine pairings of CS wh UCS plus one test trial in which the CS only was given. A randomly assigned intertrial interval of $5,10,15,20,25,30,35$, or 40 sec separated each presentation within a block of trials, and a $3 \mathrm{~min}$ rest period separated the blocks. After each UCS, the S's resistance was measured and compensations made in the shock voltage to insure the continuation of the $1 \mathrm{~mA}$ level of current. Previous to the first block of trials each $S$ received 10 presentations of CS alone; there were no reactions.

Response analysis. Two types of response were abstracted from the paper tapes. Anticipatory conditioned responses (ACRs) began after the onset of the CS but before the onset of the UCS. Test conditioned responses (TCRs) came within $1.2 \mathrm{sec}$ after the onset of the CS for every tenth trial for all groups. For statistical analysis, computer programs were written for Spearman nonparametric correlation, Wilcoxon matched-pairs signed-ranks test, and Kruskal-Wallis one-way analysis of variance (Siegel, 1956). Significances are less than .05, two-tailed.

\section{Results and Discussion}

While Fig. 1a shows some visual difference between experimental and control groups for the first day of age, there are no significant differences for 


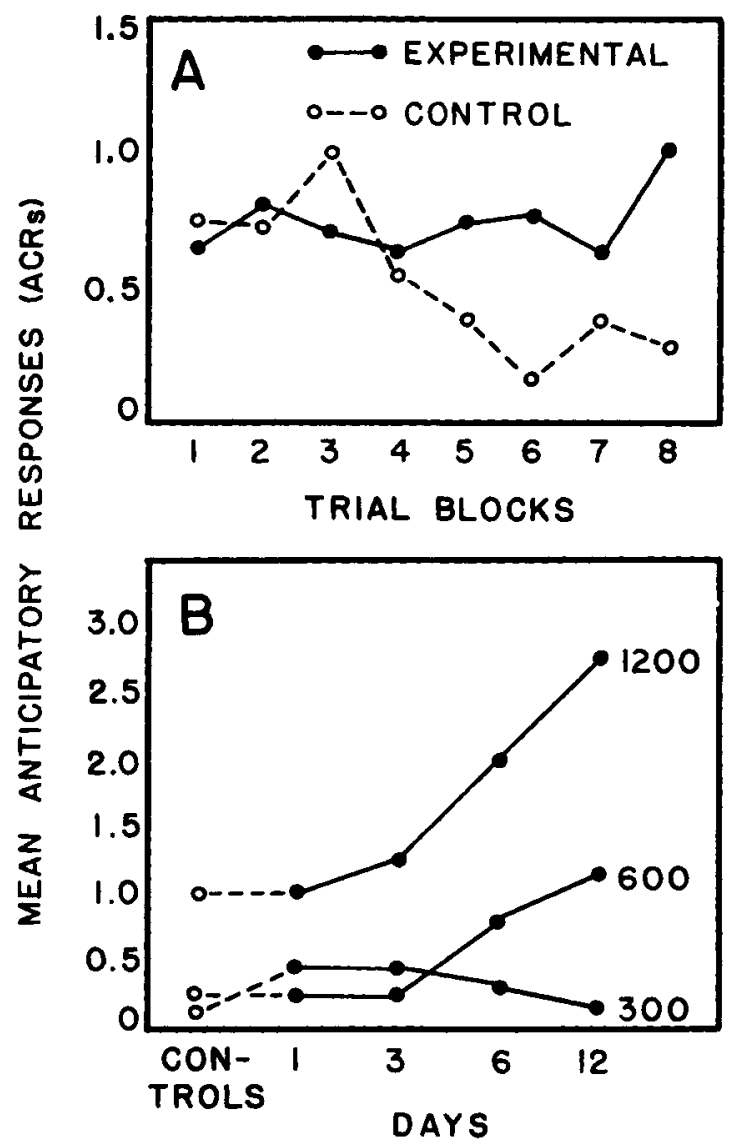

Fig. 1. (a) Conditioning on the first day of life measuring Anticipatory Conditioned Responses ( 9 per block of 10 trials) with CS.UCS interval groups combined. (b) Conditioning as a function of age and CS-UCS intervals measuring Anticipatory Conditioned Responses.

neither ACRs nor TCRs in any of the interval groups. Comparison with the Caldwell-Werboff curves indicates that their experimental groups performed a little better than ours while their control groups were less active. Needless to say, we have no explanation for either difference. However, in our study we matched the control groups to the experimental groups for each CS-UCS interval. This seemed necessary because if ACRs were to be measured then the longer the interval the more chance that random responses would be counted as learned responses. Inflated statistical differences could be avoided by comparing each experimental group with the control that had the same assumed interval between stimuli. The correctness of doing this is established by the fact that our control groups differed significantly, whereas the CaldwellWerboff control groups did not.

In this experiment, we found that learning increases as a function of age for rats conditioned with 600 and 1200 msec intervals, as shown in Fig. 1b. There are significantly more ACRs for the sixth and 12th days than for the corresponding interval controls, using nonparametric analysis of variance. In addition, TCRs are significantly more numerous for the 600 and 1200 msec intervals on the third day and for the $300 \mathrm{msec}$ interval on the 12th day. When only the ACRs are considered, the $1200 \mathrm{msec}$ interval appears to be more efficacious, but the TCRs yield a more sensitive index of learning. In other words, longer intervals are biased for the measurement of anticipatory responses. The correlation for these two measures, by the way, was 0.35 in this experiment. When the three CS-UCS intervals are compired with ACRs as the measure, there are significant group differences on each of the four days. The Caldwell-Werboff curves showed a marked increase from first to second trial blocks. A Wilcoxin analysis of our 12 experimental group means for a similar increase was significant.

There is an ontogenetic reveisal for TCRs from the first to the 12th days of age in the 600 and $1200 \mathrm{msec}$ groups. At 12 days of age the 600 msec mean score is double that of the $1200 \mathrm{msec}$ mean score, whereas on the first day the $1200 \mathrm{msec}$ interval produced better conditioning. This incrsased efficacy of the 600 msec interval with age appears to be a new finding, although Caldwell and Werboff had in effect predicted it. If extrapolated to other species, the finding would suggest that contingencies for optimum learning in aduits may not provide the best tests for learning ability in neonates. Thus, while the law of the optimum efficacy of the half-second interval between related stimuli may hold for adult and near-adult individuals, it may not hold for the neonate of such species as the white rat, where learning seems quantitatively low and qualitatively different.

\section{References}

CALDWELL, D. F., \& WERBOFF, J. Classical conditioning in newborn rats. Science, 1962, 136, 118-119.

KIMBLE, G. A. Hilgard and Marquis' conditining and learning. New York: Appleton-Century-Crofts, 1961

SIEGEL, S. Nonparametric statistics for the behavioral sciences. New York: McGraw-Hill, 1956.

Note

1. The research reported here was supported by U.S. Public Health Service Grants MH-05766 and HD-00877. 